\section{Automatic external defibrillators}

To the Editor: Dr. Brown's Commentary $^{1}$ on the proposed mandating of AED availability in US schools was a welcome commonsense and well-reasoned appraisal of the actual, rather than the perceived, need for any such program.

Unfortunately, "perception of reality" actions are frequent in modern society whereby things are proposed or undertaken to give the public a reassurance that problems have been addressed but without any evidence that those actions will result in any benefit.

My first insight into AED usage comes from my 1996 to 2004 experience of being the Medical Director of an AED Program in a gated, adult ( $>55$ years of age) community of approximately 1200 persons. The program comprised the initial training and then maintenance of skills of the 10 security guard staff. Maintenance of skills was assessed on an every 3 month basis, with a re-testing within 1 week when anyone failed a test. Tests were clinical scenarios involving assessment of the need for AED, its deployment and firing, and appropriate use of basic CPR, using a resuscitation model with a carotid pulse feature and electrode site attachments. Biweekly self-tests also had to be signed off. In our jurisdiction, the staff could only provide the AED under the medical licence of a physician. A report of any actual AED deployment had to be completed by the attendant within 24 hours of the incident and then reviewed by a physician.

My second insight comes from 22 years' experience as on-site physician and medical advisor to a private boarding school of 400-420 students, aged 12 to 18 yrs, plus providing both emergency and some regular family practice service to the academic, sports, house, and school ancillary staff. The school had a 24-hr nursing service, plus in-service training in CPR available for all staff, but it did not have an AED. Student activity, including contact-collision sports, was a 3-times-per-week occurrence, with visiting teams increasing the numbers participating.

The practical reality is that in the adult community project, where expectation of need should have been high, the AED was never required nor deployed, other than in what amounted to a human body practice (i.e., the individual had been dead for some time but the AED was used).

The financial cost of the AED program in the adult community included the capital cost of an initial AED unit plus a second (replacement) unit with a training module, a union-stipulated minimum 4 hours pay per guard per maintenance of skills session every 3 months plus a further 4 hours for retesting for anyone who failed, a unionnegotiated increase per hour because of the added responsibility of the staff using an AED, and my 3-monthly fee.

Interestingly, the AED program was terminated in mid-2004, not because of a decision that it was not needed or worth the outlay, but because the strata council's insurance company decided that it would not provide liability coverage for the AED actions of the security staff. They maintained that coverage should be provided by the supervising physician's personal medical liability insurance provider, deeming the AED action a "medical act." Not surprisingly, this was not personally acceptable, but, even if it had been, it would not have been possible because the sole provider of medicolegal insurance in Canada deals exclusively with physicians' liability. The commonsense stance that a person who is unresponsive, without a pulse, and not breathing is clinically dead and, there- fore, could not be harmed further was apparently beyond their understanding.

In the school setting, there was never a cardiac arrest in either the student or the adult population. Additionally, once a year for 3 days, the school hosts one of the largest rowing regattas in North America, with a combined student and adult attendance of around 1500. Similarly, no arrests occurred during these sporting events.

It seems fair to say that this outlined "real-time" practical experience has been broad enough to provide support for Dr. Brown's contention that the actual need for AED availability has been much exaggerated and could not be supported by what physicians are recommended to practice, namely evidence-based medicine.

Those who would wish to pursue the proposed mandatory in-school AED will likely provide some evidence to support their view. Unfortunately, there is no mandate that evidence need be good: that development would indeed be a step forward.

\section{K.M. Laycock, MB ChB(Edin), Dip Sport Med (CASM)}

PO 190, Mill Bay BC V0R 2P0

kmldoc@brentwood.bc.ca

\section{Reference}

1. Brown L. Mandating automated external defibrillators in schools: Fire, ready, aim! Can J Emerg Med 2004;6(6):4313.

\section{The decay of CTAS}

To the Editor: The Canadian Emergency Department Triage and Acuity Scale (CTAS), ${ }^{1}$ when it first was developed, served as a very useful tool by which patients could be triaged both in the hospital and pre-hospital setting. I applauded its arrival and have used it to great advantage in our community emergency department. Unfortunately, 
it has been eroded by a system that tries to squeeze more and more out of less and less.

Prior to CTAS our department had a classification of patients as Emergent, Urgent, Deferrable, or Scheduled. There was a vague understanding amongst paramedics, doctors and nurses about just what these terms actually meant, but the system generally worked well for those who had enough experience to apply it. If, for any reason, the triage nurse was particularly worried about a patient, an asterisk would be placed on the top of the chart to signify the sicker patients.

CTAS finally introduced a written scale that made sense and could reasonably be applied by any practitioner regardless of experience. I even published a small pamphlet, for patients in the waiting room, which explained the concept of CTAS and gave examples of which conditions would merit which level of urgency. There was no more need for asterisks as our team learned to triage patients correctly.

Then began the inevitable decay. The government knew that a compilation of CTAS data could be used to determine the average acuity of patients visiting a department and thereby determine its level of funding. I noticed that our nurse managers began encouraging triage nurses to "push the envelope" with triage scores so that our acuity was high enough to maintain or improve funding. This flu season I finally witnessed CTAS evolve (or mutate) from a creature of patient care into a monster of bureaucracy. Every cold or flu was a CTAS Level III. Technically, they all had difficulty breathing, didn't they? Every pain was at least an 8/10. Every child with the slightest fever was potentially meningitis and was scored as such. We have scored ourselves into a corner so that it is impossible to see all these urgent patients within the time frames suggested by the scale. And now, amongst the sea of CTAS Level IIIs that clutter my desk, the really sick ones are once again marked with an asterisk.

\section{Robert B. Reddoch, MSc, MD \\ drbob@glen-net.ca}

\section{Reference}

1. Beveridge R, Clarke B, Janes L, Savage N, Thompson J, Dodd G, et al. Canadian Emergency Department Triage and Acuity Scale: implementation guidelines. Can J Emerg Med 1999;1(3 suppl). Online version available at: www.caep.ca/002.policies/002-02.ctas .htm (accessed 15 Feb 2005).

\section{[Dr. Michael Murray responds:]}

To the Editor: The Canadian Emergency Department Triage and Acuity Scale $\left(\right.$ CTAS) ${ }^{1}$ was introduced as a tool to identify patients requiring priority care but, for several reasons, there has been "gaming" in its application. Dr. Reddoch highlights an example of misapplication of CTAS for other purposes. Optimal CTAS application requires regular audit, review, education and retraining. Without evaluation and quality improvement processes, triage standards will drift, and it is likely that CTAS levels will regress to the middle - CTAS Level III.

Recent CTAS revisions ${ }^{2}$ are based on the CEDIS chief complaint list ${ }^{3}$ and objective modifiers that allow for less subjective "interpretation" of triage levels. These revisions were necessary in order to make CTAS more objective, to ensure better standardization and more reliable comparisons between centres. They will also reduce the "gaming." The revised CTAS guidelines have been incorporated into computer assisted triage software ${ }^{4}$ that can potentially reduce inter-observer variability.

To maximize the likelihood that CTAS is being applied appropriately, emergency department leaders should review the new guidelines and develop a plan for their implementation. This plan should incorporate training, audit and CQI (continuous quality improvement) processes, and it may include computer-assisted electronic triage modules.

Comments and questions should be addressed to ctas@ caep.ca.

Michael J. Murray, MD

Chair, CTAS National Working Group

\section{References}

1. Beveridge R, Clarke B, Janes L, Savage $\mathrm{N}$, Thompson J, Dodd G, et al. Canadian Emergency Department Triage and Acuity Scale: implementation guidelines. Can J Emerg Med 1999;1(3 suppl). Online version available at: www.caep.ca/002.policies/002-02.ctas .htm (accessed 15 Feb 2005).

2. Murray M, Bullard M, Grafstein E; for the CTAS and CEDIS National Working Groups. Revisions to the Canadian Emergency Department Triage and Acuity Scale Implementation Guidelines. Can J Emerg Med 2004;6(6):421-7.

3. Grafstein E, Unger B, Bullard M, Innes G; for the Canadian Emergency Department Information System (CEDIS) Working Group. Canadian Emergency Department Information System (CEDIS) Presenting Complaint List (Version 1.0). Can J Emerg Med 2003; 5(1):27-34.

4. Bullard MJ, Dong SL, Meurer DP, Blitz S, Colman I, Rowe BH. Emergency department triage: evaluating the implementation of a computerized triage tool [abstract]. Can J Emerg Med 2004;6(3):188. 